\title{
DISCUSIONES DE LOS DOCENTES DE LENGUA ACERCA DE SU PROPIO TRABAJO
}

\author{
Stella Maris Tapia (Universidad Nacional de Río Negro -Sede Andina)* \\ stella.tapia@gmail.com / stapia@unrn.edu.ar \\ María Victoria Goicoechea Gaona (Centro Regional Universitario Bariloche - \\ Universidad Nacional del Comahue)** \\ marivi.goico@gmail.com
}

Recibido: 30/07/2012 Aceptado: 18/11/2012

\section{Resumen}

En función de estudiar cómo se aborda la articulación entre el lenguaje como una práctica y el sistema gramatical de la lengua materna en los niveles medio y superior, se organizaron tres grupos de discusiones focalizadas donde, a partir de una consigna, diferentes docentes argumentaron sobre el trabajo en las aulas y sobre la relación entre la enseñanza de los textos y de la gramática.

El enfoque del interaccionismo sociodiscursivo explica la actividad social como el origen del lenguaje y del pensamiento. En este marco, consideramos a cada texto o enunciado como el producto de una interacción social, con tres niveles de planificación que, como un hojaldre, se entremezclan: la infraestructura general, los mecanismos de textualización y los mecanismos de responsabilidad enunciativa. Los elementos que conforman estos mecanismos son utilizados, en este artículo, para analizar tres textos de las discusiones focalizadas, con el objeto de esbozar cómo los docentes dan cuenta de su propio trabajo.

\section{Palabras clave}

Gramática - Trabajo docente - Discusión focalizada - Interacción - Mecanismos de textualización y de enunciación.

* Licenciada y Profesora en Letras (UBA). Doctoranda en el Doctorado en Ciencias de la Educación, Universidad Nacional de Córdoba.

** Licenciada en Filosofía y letras, sección Filología hispánica (Universidad de Zaragoza). Doctoranda del Departamento de Ciencias de la Educación de la Universidad de La Rioja (España). 


\begin{abstract}
In order to study how the articulation of language as a practice and system of mother tongue's grammar is tackled in secondary and university education, three focusgroups were organized, where different teachers discussed, around a watchword, their classroom's work and their problems on grammar teaching.

The interaccionism's socio-discursive approach explains the origin of language and thought in social activity. In this framework, we consider one text as a product of social interaction, with three planning levels that, like a puff pastry, intermix: general infrastructure, mechanisms of textualization and mechanisms of enunciation. In this article, elements of both mechanisms are used to analyze three texts of focus groups, in order to draw how teachers account for their own work.
\end{abstract}

\title{
Key words
}

Grammar - Teacher's work - Focus group - Interaction - Mechanisms of textualization and enunciation.

\section{Introducción}

Los problemas de la enseñanza de la lengua en el inicio de la formación universitaria han sido objeto de numerosos estudios, que buscan dar cuenta de cómo aprenden los alumnos y cuáles son sus falencias en el dominio de la lectura y la escritura, en buena medida por su vinculación con cuestiones como el ingreso y la permanencia en la universidad. Menos abordada resulta la cuestión de cómo formar a los formadores, en particular, en la articulación entre lo que Bulea y Bronckart (2010) califican como dos tipos de ingenierías en la formación de los enseñantes: la que se constituye a partir de las demandas clásicas de transmisión de saberes y la que privilegia los dispositivos de análisis de prácticas a través de los cuales los profesores son confrontados con las situaciones de la actividad real, conducentes a la toma de conciencia de las características de su labor.

En torno a estas problemáticas, el proyecto de investigación "De los efectos formativos en los alumnos a la formación de formadores: la enseñanza de los razonamientos argumentativos y la gramática de las lenguas" de la Universidad Nacional de Río Negro, dirigido por Dora Riestra, continúa una línea de investigación abierta tiempo atrás en la misma institución, que plantea la necesidad de articulación entre los niveles de enseñanza medio y universitario. Su objetivo es analizar cómo se enseña a razonar gramaticalmente, de qué modo los docentes de lengua argumentan mediante el uso de razonamientos gramaticales para que los alumnos se apropien de la lengua como conocimiento epistémico o técnica semiótica (Coseriu, 1991) y puedan usar el lenguaje en la producción tanto de textos orales como escritos. El foco está puesto en las intervenciones de los docentes en relación con la didactización de los contenidos gramaticales en función de la enseñanza de los razonamientos. El motivo último de esta 
investigación es construir vías de articulación en la enseñanza de la lengua materna entre los últimos años de nivel medio y la universidad, para aportar a la formación y al desarrollo profesional de los profesores de lengua.

La hipótesis de la que partimos en este trabajo es que las acciones que realiza un docente al hacer su trabajo no pueden ser fácilmente verbalizadas por el agente de la actividad. Consideramos que el análisis de los mecanismos de cohesión verbal y los mecanismos de enunciación en discusiones focalizadas, en tanto textos producidos en entrevistas grupales con diferentes docentes, permite identificar los elementos con los cuales los docentes describen y valoran sus acciones para enseñar la lengua materna y para articular estos conocimientos de la lengua con los saberes propios de la práctica escrituraria.

\section{Marco teórico}

Bronckart (2004/2007) plantea que el estudio de la actividad de enseñanza como trabajo es consecuencia de la evolución de las investigaciones de didáctica de las disciplinas y del acercamiento entre ellas y la ergonomía o análisis del trabajo.

El enfoque teórico del que partimos, el interaccionismo sociodiscursivo, considera que mediante la actividad de lenguaje los humanos producimos los signos, las unidades de significado que permiten el desarrollo de la conciencia (Vygotski, 1934/2007). Los signos, a su vez, se organizan en textos, unidades comunicativas cuyas "condiciones de apertura, de cierre y de planificación general están masivamente determinadas por factores de orden praxeológico o cognitivo" (Bronckart, 2007, p. 74). Los textos se agrupan o indexan en géneros, en relación con la actividad no verbal que organizan, formulan o evalúan. Cada texto es portador de un contenido temático o referente, "conjunto de las informaciones presentadas explícitamente en él, es decir, las que traducen las unidades declarativas de la lengua natural que se utiliza" (2004: 62)

A la vez, cada texto empírico se organiza en tres estratos superpuestos: la infraestructura general del texto, los mecanismos de textualización y los mecanismos de responsabilidad enunciativa. Bronckart metaforiza estos niveles como un milhojas ya que se trata de una superposición de carácter jerárquico que ubica en el nivel más profundo la infraestructura, constituida por el plan general del texto, los tipos de discurso que comporta y las modalidades en que los tipos de discurso se articulan entre sí. Los mecanismos de textualización crean series isotópicas que establecen la coherencia temática, pues hacen evidente la estructuración del contenido temático; mientras que los mecanismos de asunción de la responsabilidad enunciativa son más superficiales por estar ligados al tipo de interacción que se establece entre el autor y sus destinatarios.

Los mecanismos de conexión, de cohesión nominal y de cohesión verbal son los mecanismos de textualización que organizan los elementos constitutivos del contenido temático. 
Los mecanismos de asunción del compromiso enunciativo, por su parte, conciernen a la gestión de las voces enunciativas y a la expresión de las modalizaciones; ambas contribuyen a establecer la coherencia pragmática del texto, ya que orientan "al destinatario en la interpretación de su contenido temático" (op. cit.).

Los enunciados presentan una combinación de voces que en términos empleados por Bronckart podemos resumir de la siguiente manera: los hablantes contamos con una voz neutra que corresponde a la instancia general de enunciación que asume directamente la responsabilidad de decir, es el narrador o el expositor del enunciado. Infraordenadas a ella pueden ponerse en juego una o varias voces ajenas. A éstas, Bronckart las denomina voces segundas y son: voces de personajes, voces de instancias sociales y voz del autor empírico del texto.

Según Bronckart, "La práctica de los géneros es la ocasión para los aprendizajes sociales, relacionados globalmente con la adaptación del actuar verbal a las diversas formas del actuar general. Éste es uno de los aspectos de las mediaciones formativas" (2007: 85), pero, dado que los textos en tanto unidades comunicativas se conforman por la selección y combinación de mecanismos estructurantes, operaciones cognitivas y modalidades lingüísticas de realización, en la enseñanza de lengua no resulta suficiente la práctica de los géneros para el desarrollo de las capacidades textuales de los alumnos, sino que la enseñanza de las actividades de lectura y de escritura (Riestra, 2008) tiene que complementarse con la gramática de la lengua, en tanto sistema semiótico conformado por signos arbitrarios, mediante los cuales puede realizarse la actividad del lenguaje en un momento histórico. Es por ello que Riestra $(2005,2007,2010 a)$ identifica un problema para la didáctica de la lengua en la coexistencia de dos lógicas disjuntas que no logran articularse en la enseñanza: por un lado, las acciones de lenguaje en función del contexto comunicativo, es decir, la dimensión praxeológica, y por otro lado, la dimensión epistémica, que implica una lógica proposicional o lógica gramatical.

En cuanto a la relación entre el lenguaje y el trabajo, consideramos que ambas actividades estuvieron estrechamente relacionadas en su surgimiento, ya que compartieron las condiciones biológicas-orgánicas- y sociales que determinaron su aparición y desarrollo. El trabajo es un proceso que une al hombre con la naturaleza. "El hombre pone en movimiento las fuerzas de que su cuerpo dispone -brazos y piernas, cabeza y manos- con el fin de asimilarse unas materias y darles una forma útil para su vida" (Leontiev, 1959/1983, p. 57). De esta manera, para Leontiev, el trabajo se desarrolla sobre la naturaleza exterior, modificando a la vez la propia naturaleza y conciencia humanas.

Dejours (2009) plantea la noción de "Travail vivant" (trabajo que vive) para referirse a la relación entre trabajo, cuerpo y subjetividad. Trabajar es poner el cuerpo a prueba, lo que implica el desarrollo de nuevas habilidades y de nuevos 
registros de sensibilidad. Este enfoque teórico entiende el trabajo como una experiencia que propicia el desarrollo de uno mismo o la frustración. Por tanto, para este autor, el trabajo, también, es conciencia: "Trabajar constituye para la subjetividad una prueba que la transforma. Trabajar, no solo es producir, es transformarse a sí mismo y, en la mayoría de los casos, es la ocasión para la subjetividad de comprobarse, de realizarse" (30).

El análisis del trabajo es abordado por la didáctica de la lengua con el objeto de indagar cómo determinado proyecto de enseñanza es puesto en práctica. En esta instancia se hace evidente la necesidad de preocuparse por la realidad del trabajo docente. Para ello se distinguen tres dimensiones: el trabajo real, el trabajo prescripto y el trabajo representado.

Riestra (2010b) define al trabajo representado como el conjunto de representaciones colectivas que movilizan el trabajo docente (como cualquier otro trabajo humano) que, en muchos casos, operan como representaciones sociales inconscientes. Para Riestra el trabajo prescripto es lo establecido institucionalmente. Bronckart (2004) lo considera "una representación de lo que debe ser el trabajo por encima de su realización efectiva" (171). Se ubican en este nivel "los proyectos didácticos, los programas, los manuales o las secuencias didácticas" (ídem). El trabajo real, para Riestra, es lo realizado concretamente en un determinado contexto socio histórico. Bronckart, por su parte, señala que abarca "las características efectivas de las diversas tareas realizadas por los trabajadores en una situación concreta". Asimismo, Bronckart puntualiza como característica resultante de las investigaciones del Grupo LAF (Lenguaje, Acción, Formación, Universidad de Ginebra), la opacidad del trabajo docente, es decir, la dificultad para describir dicho trabajo, para caracterizarlo o para hablar de él, por parte de los agentes que realizan la actividad. En este aspecto coincide con lo observado por Schwartz (1997) en relación con una de las dimensiones experienciales del trabajo, unas competencias prácticas que no puede explicar muy bien quien las hace, que requieren de la síntesis y de una cultura muy específica, apenas formulada o formulable, difícil de verbalizar y muy ligada al contexto. La conformación de estas competencias prácticas, para Schwartz, está en la operación misma y resultan, por lo tanto, difícilmente evaluables.

Dejours (op. cit.) explica la dificultad para la visibilidad del trabajo en la estrecha relación entre el trabajo y la subjetividad: "El trabajo no es reducible a una actividad de producción en el mundo objetivo. El trabajo es siempre una puesta a prueba de la subjetividad, pues esta última sale enriquecida" (30). Todo lo que es subjetivo, lo afectivo, no se ve. El trabajo no puede ser evaluado, pues solamente lo que pertenece al mundo visible es accesible a la experimentación científica y puede ser objeto de una evaluación objetiva. Es posible, por tanto, medir el producto del trabajo, la producción. Lo que sucede cuando uno trabaja es que con frecuencia el trabajo hábil sabe poner en juego su inteligencia, pero no llega a darse cuenta. No dispone de todos las palabras 
necesarias para describir ese trabajo efectivo, incluso es probable que el léxico, la misma lengua sea deficitaria frente a esta experiencia del cuerpo. "Todo lo que no está simbolizado del trabajo efectivo no pude ser objetivado" (28).

En didáctica de la lengua, señalan Bulea y Bronckart (2010) que los aportes de la ergonomía y de la clínica del trabajo, articulados con el estudio de los cambios en los documentos prescriptos (reformas curriculares, de objetos de enseñanza, que se propician a partir investigaciones realizadas por los teóricos y los didactas, por ejemplo) permiten dar cuenta de que existe un dominio de las prácticas de enseñanza efectivas en clase, cuyo análisis no puede ser independiente, en la formación de formadores, de la "re-interrogación" de los conocimientos teóricos.

\section{Metodología}

Las entrevistas grupales o discusiones focalizadas son métodos de recolección de datos en nuestro proyecto de investigación. Consisten en entrevistas múltiples donde se promueve la interacción entre los entrevistados, porque se instala una situación de debate en torno a una pregunta abierta, a la que denominamos consigna de discusión.

Se desarrollaron tres discusiones focalizadas, dos de ellas conformadas por grupos de cuatro integrantes, y la restante, por tres integrantes, en los meses de noviembre y diciembre de 2011. Los participantes de uno de los grupos habían trabajado en la materia Introducción a la Lectura y la Escritura Académica, en la Sede Andina de la Universidad Nacional de Río Negro, además de ser docentes en ejercicio en escuelas secundarias de San Carlos de Bariloche. Los otros dos grupos estaban integrados por profesores de nivel secundario, también de Bariloche. Las discusiones focalizadas fueron introducidas por una integrante del equipo de investigación en su rol de Coordinadora. Ésta participó inicialmente para explicar la consigna en torno a la cual se iba a debatir, la modalidad de trabajo y, al finalizar el tiempo otorgado al debate (de, aproximadamente, media hora) retomó la palabra para realizar un cierre. Se entregó a cada uno de los participantes, por escrito, el siguiente problema a partir del cual debatir: "Proponemos a los alumnos planificar la escritura un texto. Los alumnos elaboran la planificación, pero escriben el texto espontáneamente. Ante esos textos, pedimos que los reescriban mejor. ¿Qué hacemos para que "reescriban mejor"? ¿Abordamos los problemas gramaticales o los dejamos que reescriban varios borradores?". La información de cada discusión focalizada se registró a través de una grabación en audio que fue desgrabada y transcripta para su análisis.

El producto de cada transcripción es un texto que fue analizado, en primer término, con un criterio de relevancia para la investigación. De tal forma se ubicaron algunos conceptos que permiten organizar temáticamente los textos 
y segmentar enunciados, que representan las opiniones de los participantes acerca de su trabajo. Cada enunciado, es, pues, una unidad de análisis.

Una vez delimitados temáticamente los enunciados, y con el objeto de analizar cómo caracterizan los propios docentes su actividad de enseñar la lengua en articulación con las prácticas de lenguaje, se identifican, en un segundo nivel, siguiendo la metodología de análisis de la arquitectura textual desarrollada por Bronckart (2004), por una parte, algunos mecanismos de cohesión verbal (en el plano de los mecanismos de textualización) que permiten dar cuenta de cómo conciben y cómo caracterizan los docentes a las acciones que realizan, vg., si se perciben como sujetos de las acciones que realizan y, por otra parte, las modalizaciones (en tanto mecanismos de asunción de la responsabilidad enunciativa) a través de las cuales detectar cómo los docentes describen y evalúan su trabajo.

\section{Análisis}

\section{Aspectos temáticos}

Los contenidos temáticos desarrollados en los textos permitieron la segmentación de 29 enunciados en relación con la consigna que organizaba las discusiones focalizadas y que, a su vez, en el marco del proyecto de investigación, nos indican cuáles son los problemas que atañen a la enseñanza de la lengua. Los tres temas recurrentes en estos enunciados son la escritura, el error y la gramática.

En relación con la escritura, se reconocen los siguientes subtemas:

- la escritura como proceso (se repite 2 veces),

- la escritura y la reescritura (en 2 oportunidades),

- la escritura según el tipo de texto (2 veces),

- la escritura a partir de una planificación y una secuencia,

- relación entre lectura y escritura (2 veces),

- las motivaciones para escribir,

- la escritura como oficio.

Con respecto a los errores, los subtemas abarcan:

- corrección del error por parte del docente (3 veces),

- marcar el error para que luego se lo revise (3 veces),

- los errores gramaticales (2 veces).

En cuanto a la gramática, los subtemas son:

- problemas gramaticales (2 veces),

- el abordaje de la gramática a partir de producción y la contextualización (3 veces),

- la resolución intuitiva por oposición a la fundamentación gramatical,

- la gramática como regla o "formulita". 
Otros temas son la primacía de la ortografía sobre el sentido del texto (sobre lo que se quiere decir), la desvalorización de la sintaxis y la necesidad de sistematicidad en la enseñanza de la lengua.

\section{Aspectos lingüísticos}

Un segundo nivel de análisis atiende a los mecanismos de cohesión verbal (un mecanismo de textualización) para ubicar las acciones referidas en los enunciados. En particular, observamos algunos verbos y los roles sintácticos atribuidos a los protagonistas del actuar formativo. Bronckart (2004) señala que la tradición gramatical sólo hacía una distinción entre los verbos de estado y a los verbos de acción, pero, siguiendo a Vendler, se identifican cuatro clases de verbos: verbos de estado, verbos de actividad, verbos de realización y verbos de logro. No obstante, advierte sobre el carácter cuestionable de tal calificación si no se manifiestan en interacción con otras funciones de cohesión verbal.

Por su parte, la Real Academia Española (2010) califica el aspecto léxico, modo de acción o cualidad de la acción de los verbos y de sus correspondientes predicados en cuatro clases: 1 . Actividades, 2. Realizaciones o efectuaciones, 3. Consecuciones o logros, 4. Estados. Estos se caracterizan según tres rasgos: duración, delimitación y dinamismo. Así, las actividades poseen rasgos de duración y dinamismo; las consecuciones y las realizaciones comparten rasgos de delimitación y dinamismo, aunque no de duración. Los estados, en cambio, sólo se caracterizan por la duración. Mientras que los verbos de estado remiten a procesos durables, y por tanto, excluyen la dinamicidad o el cambio, los verbos de actividad, de realización y de logro implican procesos dinámicos, es por ello que para nuestro análisis sólo consideramos a estas tres últimas clases. Discriminamos los verbos de estado y los verbos que forman parte de voces ajenas introducidas en el texto, porque se corresponden con mecanismos de asunción de la responsabilidad enunciativa.

En siete enunciados no hay verbos en primera persona del singular cuyo sujeto sea el docente. Se utilizan, en cambio, formas impersonales y voces pasivas, uso de la tercera persona del plural (ellos) para referirse a lo que los alumnos hacen y perífrasis con construcciones como "hay que" (ver supra: modalizaciones). A modo de ejemplo, en el siguiente enunciado cuyo tema es la escritura puede señalarse la ausencia de verbos de actividad, logro o consecución, en primera persona del singular cuyo sujeto sea el docente:

El tema de la planificación me parece que ellos por ahí, se hace, no sé si sería correcta la palabra, instintivamente, ellos tienen acá (tocándose la frente) más o menos la planificación de lo que quieren hacer. Cuesta un poco trabajarlo y que ellos expliciten por escrito los pasos que van a hacer para realizar ese texto y que vayan realizando efectivamente esos pasos, me parece. Eso es lo que no se explicita en los trabajos. Uno va y les da la consigna de escritura y 
bueno, después miramos el texto, y como que nos centramos en el producto, también, ¿no? Nosotros como profesores, y no: "A ver, de qué manera pensaste vos escribir este texto, ¿cuáles fueron los pasos que fuiste realizando?" Esto de que a veces vuelven sobre lo que escribieron, deshacen, como harían con un procesador de textos, quizás, que por eso decías vos que se visualizan mejor estos aspectos cuando se trabaja con un procesador de texto.

Se observa el uso de la impersonalidad mediante un sujeto "uno" o mediante formas pasivas ("se hace", "se explicita", "se trabaja", que hemos marcado con negritas). Hay verbos en tercera persona del plural cuyos sujetos gramaticales son los alumnos ("expliciten", "van a hacer", "vayan realizando", "vuelven", "escribieron", "deshacen", "harían", marcado con negrita e itálicas). Vemos que en este enunciado, la mayor cantidad de acciones son atribuidas a los alumnos. Otros verbos que se refieren a la acción docente ("miramos", "centramos", subrayados en el ejemplo) están conjugados en primera persona del plural, concordando con un sujeto que se explicita posteriormente: "Nosotros como profesores".

En otros cuatro enunciados, la acción del docente es referida mediante la segunda persona del singular (por ejemplo: "no lo entienden tampoco cuando lo planteás en la explicación, evidentemente no se entiende"), lo que podría quizás atribuirse a la situación comunicativa de la discusión focalizada, porque se inserta en el diálogo de los enunciados.

La primera persona del plural ("nosotros") a veces se utiliza para indicar el colectivo docente- alumnos, lo que docente y alumnos hacen en el aula, y otras veces, para referirse al colectivo de los docentes ("nosotros los docentes"), que también podría explicarse a partir del dialogismo de la discusión focalizada - en tanto que cada docente destina su enunciado a los colegas presentes. Como vemos en el siguiente ejemplo, pueden incluso utilizarse ambas formas a la vez:

Ante una propuesta de escritura ellos creen que lo único que nosotros vamos a mirar es la ortografía. Entonces están más pendientes de eso que del contenido que ellos quieren volcar al texto. Entonces también ahí como que vamos haciendo algunos pactos: bueno, en la primera escritura tengan en cuenta lo que quieren decir y después miramos la ortografía. Porque eso los condiciona mucho, y quizás porque ellos traen incorporado esto de que lo único que miramos nosotros son los errores ortográficos, ¿no?

En el enunciado, se atribuye a los alumnos (ellos) el verbo "creen" en contraste con el sujeto nosotros (docentes) al que se atribuye "vamos a mirar", que coexiste con otro sujeto nosotros "vamos haciendo algunos pactos" y "miramos la ortografía" (ellos alumnos y yo docente). Retoma luego el colectivo "docentes" ("miramos nosotros") frente a "ellos alumnos". 
Doce de los veintinueve enunciados analizados presentan un rol sintáctico del docente como protagonista del actuar formativo marcado por una primera persona del singular que realiza una acción. En el ejemplo, que forma parte de uno de los enunciados, puede verse la acción del docente que narra su trabajo:

Normalmente yo, cuando HAGO escribir algo espontáneo y después lo CORRIJO, lo primero que HAGO cuando tengo ya la corrección es, en mi casa, PASO todos los errores como clasificándolos o poniéndolos bajo distintos rubros...

Los verbos que predominan, conjugados en primera persona del singular y con el rol sujeto-docente son "hago" (9 veces sobre un total de 49 verbos), "pongo" (en 8 oportunidades), "corrijo" (3 veces), "entrego" (3 veces), "explico" (3 veces), "doy" ( 2 veces). Puede notarse que algunos de los verbos más utilizados (hacer, poner, dar) son verbos llamados livianos o ligeros, esto es, formas que darían cuenta de la labilidad con la que los agentes perciben la acción formativa realizada. En otras palabras, en contraste con verbos como "enseño", "explico", "corrijo", "subrayo", "leo" cuyo significado resulta concreto en cuanto a la acción realizada por los docentes, los verbos "hacer", "poner" y "dar" serían indicios de que la acción realizada no puede verbalizarse específicamente.

Puede establecerse una relación entre los ejes temáticos y los roles sintácticos atribuidos a los protagonistas del actuar formativo: cinco enunciados que usan verbos en primera persona del singular se refieren al tema corrección de errores; tres, a aspectos gramaticales o problemas gramaticales y otros tres, a la escritura. Por último, un enunciado lo utiliza para remarcar la posición del docente ("doy sintaxis") frente a la desvalorización de la sintaxis que supuestamente circula entre los otros docentes. Vemos entonces que el docente se ubica como protagonista de su acción formativa centralmente en la tarea de corregir y proveer información para subsanar los errores.

Si enfocamos los objetos de enseñanza que se infieren de cada uno de los enunciados, predominan la ortografía y la sintaxis (ambas, parte de la gramática) asociadas a las acciones que el docente realiza al corregir los errores. Cuando el objeto de enseñanza es la actividad de escritura, los verbos que utilizan los docentes para referir sus acciones son menos precisos, además de haber menor cantidad de verbos en primera persona que cuando los docentes relatan cómo corrigen.

En relación con los mecanismos de asunción del compromiso enunciativo, entendemos las modalizaciones como evaluaciones que contienen los textos sobre diversos aspectos del contenido temático. Bronckart (2008) establece tres funciones de modalizaciones: lógicas, deónticas y apreciativas, en consonancia con Habermas (1988), quien distingue tres mundos que constituyen el sistema de referencia de los hablantes. Las modalizaciones lógicas dan cuenta de las representaciones de los hablantes acerca aspectos del contenido relacionadas 
con las coordenadas formales que definen el mundo objetivo. Las deónticas se refieren a aspectos relativos a valores, opiniones y reglas que conforman el mundo social. Las apreciativas consisten en evaluaciones de elementos de contenido vinculadas con el mundo subjetivo de la voz que enuncia.

Respecto de la voz que enuncia, los hablantes disponemos de mecanismos lingüísticos para construir la forma que deseamos darle a nuestro texto. A menudo, sobre todo en los textos orales estas decisiones son inconscientes, por eso podemos analizar si el docente en su texto asume como propia la responsabilidad de lo dicho o diluye esa responsabilidad utilizando otras voces. Una forma de diluir responsabilidad es utilizar la voz neutra (veremos ejemplos), otra forma muy abundante en las discusiones que analizamos es utilizar voces de personajes (Bronckart, 2004), en este caso voces colectivas, la de los docentes de lengua y la de los alumnos de nivel secundario. También se emplean lo que Bronckart denomina voces sociales: "iEs que es mala palabra sintaxis, me parece!".

En el ejemplo siguiente se puede ver la presencia simultánea de marcas lingüísticas correspondientes a los distintos tipos de modalizaciones. Con negrita, hemos marcado las modalizaciones lógicas, se han subrayado las deónticas y empleamos itálica para la apreciativa:

Inevitablemente, digo, hay que marcar los problemas gramaticales, ahora, la idea tampoco es darles la formulita gramatical, eh, creo que como bien dice él hay que marcarlos, hay que decir: "bueno, acá está este problema" y que reescriban, eh. Por ahí mi experiencia no es tan vasta como la de los otros chicos, pero me parece que hay un problema ya con la reescritura. A mí me ocurrió en estos años que, cuando el alumno coloca el punto final, es bastante difícil convencerlo de que reescriba

Exactamente. $Y$ el tema de la reescritura, y el tema de la reescritura me parece que habría que como darle el valor que tiene, que desde el vamos que ellos sepan que no es que van a escribir una vez, que van a escribir muchas veces, y que saber la regla gramatical tampoco les garantiza eh, tener una buena producción.

Que es una de las patas, digamos, pero que la producción tampoco se resuelve con conocimiento

Las modalizaciones deónticas en este segmento muestran el deber ser en torno a cómo proceder frente a los errores gramaticales que los alumnos presentan. Sin embargo, el docente no se refiere a sí mismo, sino que prefiere formas lingüísticas impersonales para compartir una norma supuestamente aceptada. Las modalizaciones lógicas refuerzan las aseveraciones mediante adverbios referidos a las condiciones de verdad de tales normas.

Referidas a la escritura, las modalizaciones deónticas evalúan el tema de la corrección del error y las obligaciones de los alumnos después de la devo- 
lución de un texto corregido, es decir, marcado por el profesor. La corrección es un sistema normativo que el docente comparte con los alumnos en función de la adquisición de una norma mayor, la norma lingüística correcta. El alumno reescribiendo, en la práctica, a partir de las marcas de la corrección, deberá dar cuenta de la apropiación de las normas compartidas por los hablantes de su lengua.

Las modalizaciones apreciativas se mezclan con los otros tipos: creo que como bien dice él refleja coincidencia total con lo aceptado por la comunidad docente; me parece que hay un problema: todos reconocen la existencia del problema.

El siguiente enunciado recoge la valoración, la presentación de la actividad de escritura (mediante modalizaciones lógicas) como "lo que no es" (no es algo espontáneo) reforzada con la percepción de lo normativo (modalizaciones deónticas) acerca de "qué es texto".

Y habría que partir diciendo que la escritura, haciendo ver que no es algo espontáneo, sí, que la producción puede llegar a ser, que tiene varias instancias para que un texto pueda llegar a ser

Un acuerdo compartido (modalización deóntica, "lo que un texto puede llegar a ser") da la pauta de lo que se puede considerarse como texto y de lo que no lo es.

En relación con el trabajo docente, el análisis de las modalizaciones nos permite ver, pues, que los profesores se apoyan en la norma, que se relaciona con el trabajo tal como es prescripto, más que en lo que efectivamente sucede en las clases. El análisis de los 29 enunciados seleccionados a partir de las discusiones focalizadas muestra un amplio predominio de las modalizaciones deónticas y lógicas.

Con respecto al análisis de las voces, los enunciados en los que el agente (docente) no logra dar cuenta de lo que hace en el aula, se refieren a la generalidad de lo que, se supone, sucede en las clases de lengua, mediante el empleo de una voz neutra (tercera persona de singular). En estos casos se muestra una suerte de "deber hacer" colectivo, y la responsabilidad de lo dicho recaería en el colectivo de docentes:

Pienso que una vez leídos todos los textos sí, se abordan los problemas gramaticales, y se individua cuáles son los temas, que parece que primero que hay, si hay un problema que se repite, se explica para todos, [...] con ejemplos en el pizarrón, para que no vuelva...; para que los practiquen y los mismos alumnos se vayan dando cuenta, como que tomen conciencia de cuáles son esos errores en primer lugar. Ya que seguramente sí, sí se abordan los problemas gramaticales 
Otras veces el profesor en primera persona expresa algún aspecto de su hacer, pero en seguida pasa a hablar de lo que hacen o deberían hacer los alumnos, por lo que podemos afirmar que puede verbalizar el hacer del otro, no el propio:

...yo siempre trato de hacer una puesta en común entre todos, ¿no? Algún tipo de corrección grupal, que ellos mismos puedan descubrir qué es lo que no, por decirlo de alguna manera, que es lo que no les suena bien del trabajo de un compañero, eh, y desde ahí quizás poder abordar algunos temas gramaticales

No quizás como dando la "formulita", pero sí desde la comprensión, el saber por qué no sería correcto utilizarlo de esa manera, y sobre, sobre la base de esa corrección grupal, bueno, ahí dialogar, a ver, bueno, cómo podríamos todos mejorar ese trabajo. Obviamente que después es otro tema, bueno, cómo hacés para reescribirlo, si hay ganas o no hay ganas o cómo los motivás para que lo vuelvan a reescribir o modificar. Pero la corrección grupal siempre la hago. Leemos, a ver, somos 30 , no podemos leer los 30 trabajos, pero quizás leemos 10 , si fueron 10 cuentos o fueron, no sé, 10 ensayos, eh. $Y$ ahí vamos charlando entre todos, la diferencia entre cada ensayo, qué opinan, por qué hay diferencias, desde donde lo pudo haber abordado uno, desde dónde el otro.

En otros enunciados el docente se refiere en primera persona singular a su trabajo en el aula, pero solo puede verbalizar casos muy concretos, a modo de anécdota: cuando los alumnos escribieron un género textual (informe) sobre un tema que a ellos les gustaba (género musical) o el profesor compara el hacer de los alumnos en función del curso.

En el mismo tono se encuentran los enunciados que se refieren a la actividad de lectura, a la enseñanza de esta actividad ofreciendo a los alumnos un modelo para que automáticamente los alumnos aprendan:

...cuando uno lee a los alumnos, digo como lector experto planteándolo desde ese punto de vista; ellos, en general, son lectores menos experimentados. Uno está también creando las condiciones sin decirlo, para que esa forma de usar el texto escrito tenga cierta significación que (alguien asiente), no está dicho, pero con la creación de las condiciones es como decirlo sin palabras. Entonces, me parece que leerles... cualquier texto... Pero... Bueno, acá el pero está cambiando la línea de lo que está diciendo anteriormente. Algunas explicaciones... Uno va creando ciertas condiciones para que vayan, después, usando la lengua escrita que uno va leyendo, más al leerlo, que ellos, un poco, lo asocian con la oralidad que tienen, pero con las formalidades de lo escrito. 
Comentario aparte merece el enunciado que refiere, justamente, una práctica presentada como poco habitual:

...pero los chicos no leen lo que entregan; escriben, terminan de escribir y entregan (otra docente asiente), pero si en alguna oportunidad ponemos en común todo el material, todo lo que ellos han producido, se dan cuenta cuando escuchan lo que escribieron que cometieron errores. En muchos casos me resulta más, si los leo anónimamente y, entonces se los vuelvo a entregar y ellos, muchas veces, incluso espontáneamente te piden para corregir, porque se dieron cuenta al escuchar los textos que cometieron errores.

Los enunciados mediante los cuales los docentes logran dar cuenta de su hacer son muy detallados cuando el tema es la corrección de los errores, mientras que son vagas y breves las intervenciones verbales que se refieren al orden gnoseológico o epistémico: el docente dice que enseña sintaxis o que la marcación del error está acompañada de una explicación, pero no se detalla cómo se enseña o en qué consiste dicha explicación:

¡Es que es mala palabra sintaxis, me parece! Yo doy sintaxis, aunque no tenga que dar, doy. Hay como una desvalorización de la gramática que muchos profesores la hacen notoria, y de la sintaxis, que a mí no me parece, siempre y cuando la adecuemos bien a la producción. O sea, esto tiene sentido.

Puede observarse en ese enunciado, como en otros, cierta imprecisión al hablar acerca de cómo se realiza esa enseñanza.

\section{Discusión}

La delimitación temática nos permite observar que en algunos de los enunciados se enfoca la escritura como actividad y en otros, el sistema gramatical de la lengua. Más difusa resulta la categoría "error", pues puede notarse en el producto textual, pero su origen se hallaría en diferentes niveles de la arquitectura textual.

Al analizar los enunciados a partir de la vinculación entre la lógica epistémica y la lógica praxeológica, se observa que la mayor parte de ellos (20 de los 29) se refieren al orden praxeológico únicamente, con predominio de las modalizaciones deónticas (lo que los docentes consideran que se debe hacer). Pocos enunciados ( 7 del total) se refieren al hacer y mencionan simultáneamente la gramática (categoría gramatical, reglas), como orden epistémico o soporte para el hacer; en ellos predominan, asimismo, las modalizaciones deónticas. Dos enunciados breves se refieren únicamente al orden epistémico. De esto podemos inferir que el trabajo representado por los docentes considera lo que ellos y lo que los alumnos deben hacer, en el orden de la práctica. 
De la escasa presencia de marcas en primera persona del singular que den cuenta de la acción del agente formativo en relación con la escritura, y por la prevalencia de la intervención del docente en un rol protagónico con respecto al error, podría interpretarse que el docente se percibe como el poseedor del saber gramatical y ortográfico para enseñarlo a partir de los errores de los alumnos, en una segunda etapa, pero no necesariamente en articulación con la actividad de escritura; en tanto que los que realizan las acciones para desarrollar las actividades de escritura son los alumnos, quienes, por ello, se conciben en las discusiones focalizadas como los que cometen errores ya que no podrían volcar los conocimientos de la técnica de su lengua en las prácticas de escritura. Dicho de otro modo: el docente se percibiría como corrector del error más que como agente que explica el conocimiento epistémico; eventualmente, si se consigue alguna articulación entre este conocimiento y el hacer textual, es por intermedio de la instancia de revisión y corrección de la escritura. En los enunciados analizados, no se visibiliza una acción concreta de enseñanza de la gramática articulada con el hacer textual.

En síntesis, el contenido temático de los enunciados analizados trata sobre el "hacer" en el aula. Es decir, se refieren al orden praxeólógico en detrimento del orden gnoseológico poco desarrollado, con poca presencia en los textos de los docentes.

\section{Conclusiones}

Como nuestro análisis de las discusiones focalizadas se ubica en el terreno del trabajo representado, no podemos afirmar si se lleva a cabo o no una acción de enseñanza de la gramática en articulación con la actividad de escritura porque no estamos analizando el trabajo efectivo de los docentes en el aula. La manera en que los docentes dan cuenta de su trabajo, por el empleo predominante de determinados verbos en sus enunciados, parece indicar una dificultad para verbalizar la acción realizada en clase. Además, como ya dijimos, cuando el objeto de enseñanza es la actividad de escritura, los verbos que utilizan los docentes para referir sus acciones son poco precisos.

Los docentes explicitan su trabajo concreto en clase cuando se refieren a la corrección (marcas, códigos, procedimientos que han de seguir los alumnos, etc.). En general, este tema aparece en enunciados detallados, que denotan los procesos de didactización que estos docentes realiza para enseñar la norma, la ortografía y, a veces, la sintaxis en los textos que sus alumnos escriben. Sería abundante la información que los profesores aportan a sus alumnos a través de los códigos que cada docente elabora y comparte con ellos para hacer efectivo el trabajo mutuo de corrección y, por ende, de aprendizaje. Parece que ésta es la forma en que los profesores perciben que articulan la enseñanza de la gramática con la realización de textos por parte de sus alumnos. Asimismo, aunque hemos destacado en nuestro análisis los enunciados en los que se 
menciona un desarrollo epistémico en las clases, la presencia de este orden sería escasa y, por lo tanto, no serían abordadas o no se puede dar cuenta de otra manera, excepto a partir del error, de las dificultades que se observan en los escritos de los alumnos en relación con la gramática de su lengua.

Observamos las dificultades para narrar la propia práctica de los docentes que, creemos, es un primer elemento para contrastar con lo que efectivamente hacen en el aula (trabajo real). Seguir estudiando las clases y analizando las prácticas mediante entrevistas después de su realización son los pasos sucesivos en este proyecto de investigación, para que los docentes puedan develar y tomar conciencia de lo realizado, pues, de esta forma, podrán dominar el marco de sus acciones posicionándose como legítimos actores. Así, será posible analizar didácticamente los problemas de la enseñanza de la lengua (en nuestro caso, la articulación entre la gramática y el hacer textual) en las clases, y en el trabajo que el docente realiza en las aulas, para poder aportar, desde las investigaciones, a la formación didáctica.

\section{Referencias bibliográficas}

- Bulea, E. y J.-P. Bronckart (2010). Les conditions d'exploitation de l'analyse des pratiques pour la formation des enseignants, Linguarun arena, Revista do programa doctoral em Didáctica de linguas da Universidade do Porto, Vol. 1, № 1, 2010, 43-60.

- Bronckart, J-P. (2004). Actividad verbal, textos y discursos. Por un interaccionismo socio-discursivo. Madrid: Fundación Infancia y Aprendizaje.

- Bronckart, J-P (2007). Desarrollo del lenguaje y didáctica de las lenguas. Buenos Aires: Miño y Dávila.

- Bronckart, J-P (2008). Genres de textes, types de discours et «degrés» de langue, Texto!, Vol. XIII, N $\mathrm{N}^{\circ}$, janvier 2008.

- Coseriu, E. (1991). El hombre y su lenguaje: Estudios de teoría y metodología lingüística. Madrid: Gredos.

- Dejours, C. (2009). Travail vivant. Vol. 2: Travail et émancipation. Paris: Payot.

- Habermas, J. (1988). Teoría de la acción comunicativa. Madrid: Taurus.

- Leontiev, A. (1959/1983). El desarrollo del psiquismo. Madrid: Akal.

- Riestra, D. (2005). Didáctica de la lengua. Acerca de las dificultades de la práctica: la enseñanza de las nociones gramaticales. Un enfoque histórico-cultural, Propuestas. De la problemática de las aulas a las propuestas concretas. Rosario: CELA.

- Riestra, D. (2007). Los textos como acciones de lenguaje, un giro epistemológico en la didáctica de la lengua, Co-herencia, vol. 4, núm. 7, julio-diciembre, 2007.

- Real Academia Española y Asociación de Academias de la Lengua Española (2010): Nueva gramática de la lengua española. Manual. Buenos Aires: Espasa

- Riestra, D. (2008). El razonamiento gramatical, entre el uso y el sentido de los textos, H. Manni (comp.), Actas del Congreso de la Sociedad Argentina de Lingüística. Universidad Nacional del Litoral.

- Riestra, D. (2010a). Para debatir. ¿Cómo surgen y cómo llegan las propuestas didácticas?, El toldo de Astier. Propuestas y estudios sobre enseñanza de la lengua y la literatura. Año 1, Nro. 1, octubre de 2010. 
- Riestra, D. (2010b). El trabajo docente en la enseñanza de la lengua: Los textos y el análisis entre los géneros y los tipos de discurso. En V. M. Castel y L. Cubo de Severino (ed.), La renovación de la palabra en el bicentenario de la Argentina. Los colores de la mirada lingüística. Mendoza: $\mathrm{FFyH}, \mathrm{UNC}$.

- Schwartz, Y. (1997). Les ingrédients de la compétence : un exercice nécessaire pour une question insoluble, Education Permanente, 133, 4, 1997, 9-34.

- Vigotski, L. S. (1934/2007). Pensamiento y habla. (Trad.: A. González). Buenos Aires: Colihue. 